processes of the emergence and intensification of tensions in the labor sphere of the Volga Federal District are analyzed on the base of federal and regional statistics. Employee dissatisfaction with working conditions is one of the key factors in the growth of tensions in the work collective. The authors conclude that the current steps taken to ease the tensions based on a unilateral perspective on the situation by the parties to the labor relations often become irritating and lead to the escalation of tensions in this area.

Keywords: labor sphere, labor relations, tensions in the labor sphere, tension factors, work satisfaction, unreported employment, part-time work

ОЛЕЙНИК Светлана Анатольевна - соискатель кафедры социальных технологий и государственной службы Белгородского государственного национального исследовательского университета (308015, Россия, г. Белгород, ул. Победы, 85)

\title{
ОСОБЕННОСТИ ГОСУДАРСТВЕННОЙ ПОЛИТИКИ ИНТЕГРАЦИИ ИММИГРАНТОВ В ПРИГРАНИЧНЫХ РЕГИОНАХ
}

\begin{abstract}
Аннотация. В статье рассматриваются различные особенности реализации государственной миграционной политики в отношении мигрантов в приграничных регионах. Подчеркивается необходимость проведения политики, направленной на интеграцию мигрантов в принимающее сообщество. Автор делает вывод, что одной из ключевых задач государственной политики в данной области должна стать организация регулярного мониторинга миграционной среды приграничья на основе трех групп индикаторов: социально-психологических, этнокультурных и социально-экономических. Автор предлагает создать в приграничных регионах единую управляющую систему, в работу которой должны быть вовлечены все государственные и общественные субъекты, осуществляющие деятельность в области интеграции мигрантов.
\end{abstract}

Ключевые слова: миграционные процессы, интеграция мигрантов, приграничные регионы.

Мграционные процессы в сегодняшней геополитической реальности ока-
зывают существенное влияние на развитие всех государств без исключе-
ния. Повышается роль и значение приграничных регионов, так как размыва-
ется граница между внутренней и внешней политикой, растет международная
активность регионов и других объектов федеративных государств [Межевич
2006]. Это обусловливает необходимость выработки действенных механизмов
интеграции иммигрантов в принимающее сообщество с учетом максимальной
пользы для всех сторон данного процесса.
Интерес исследователей к изучению проблем интеграции мигрантов в при-
нимающее сообщество возрастает в геометрической прогрессии. Многие из
них сходятся в мнении, что иммиграция в ближайшие десятилетия может стать
единственным источником снижения уровня депопуляции [Бормотова 2020].
Вместе с тем ряд ученых в своих работах обращают внимание на негативные
стороны массовой миграции. По мнению В.И. Мукомеля, «массовый приток
полиэтничных мигрантов - ввиду сокращения миграционного потенциала
соотечественников - станет глобальным вызовом», если на достойном уровне
не обеспечить их интеграцию. Самым негативным сценарием может стать 
«социальная исключенность» мигрантов, что, в конечном счете, приведет к дестабилизации всех сфер жизни принимающего сообщества [Мукомель 2016].

Интеграционные практики зарубежных стран разнообразны, они формируются с учетом особенностей исторического развития и конкретных условий в каждой отдельно взятой стране [Малахов 2015]. Если в качестве основных критериев использовать тип организации экономики, возможность доступа к получению гражданства и тип социальной защиты, то существующие в мировой практике интеграционные стратегии условно можно разделить на три категории: либеральные (Канада, США, Великобритания), частично закрытые (Швеция, Германия, Австрия, Швейцария) и формирующиеся (Греция, Италия, Испания, Португалия) [Мигранты, мигрантофобии... 2014].

Общей тенденцией, характерной для большинства европейских государств, является централизованное регулирование интеграционных процессов на национальном уровне посредством создания соответствующей институциональной структуры.

Например, в Дании функционирует Министерство по делам беженцев, интеграции и иммиграции, в Нидерландах разработкой и реализацией интеграционных проектов занимается Министерство жилищной политики, местных общин и интеграции, в Великобритании создан Департамент по делам местных общин, в Ирландии учреждена должность министра интеграционной политики. При этом каждое государство имеет право устанавливать свои интеграционные рамки, не выходящие за пределы общеевропейского курса в данной области.

Все разработанные в Европе программы интеграции в той или иной степени задействуют следующие составляющие:

- организацию работы «горячих линий» для мигрантов на различных языках (исходя из структуры миграционных потоков);

- языковые и иные интеграционные курсы;

- «Настольный справочник мигранта», содержащий адреса и телефоны различных организаций и центров;

- функционирование медиагрупп, призванных быть связующим звеном между мигрантским и принимающим сообществами.

Очевидно, что усложнение миграционных процессов потребовало разработки критериев оценки эффективности интеграционной политики в области миграции.

Первые попытки разработки интеграционной политики были предприняты в 1960-1970-х гг. в Швеции и Нидерландах. В 2004 г. группа европейских аналитиков создала единую систему оценки интегрированности прибывших в государства ЕС иностранцев, получившую название «Индекс миграционной политики» (MIPEX), которая на сегодняшний день включает 167 показателей и позволяет получить многомерный интеграционный профиль любого государства. Данная шкала сегодня применяется не только в Европе, но и в США, странах Латинской Америки и ряде стран Азии.

В 2020 г. Центр социокультурных исследований НИУ ВШЭ провел анализ политики интеграции Российской Федерации. Исследование проходило в два этапа и включало в себя анализ 8 сфер жизни общества: доступа к рынку труда, воссоединения семей, доступа к образованию, политической вовлеченности, института вида на жительство, доступа к гражданству, борьбы с дискриминацией, здравоохранения.

Данное исследование показало, что политика интеграции иммигрантов в России в настоящее время организована на достаточно низком уровне и требует значительной модернизации. Так, среди 52 стран, где проводился мони- 
торинг, наша страна по всем показателям занимает только 49-е место, оставаясь при этом одним из крупнейших государств, принимающих мигрантов. Согласно классификатору системы MIPEX, в РФ по состоянию на 2020 г. существует «иммиграция без интеграции», имеются достаточно высокие административные пороги для получения легального статуса, наблюдаются низкий уровень трудовой мобильности, неблагоприятные условия доступа к сферам образования и здравоохранения на фоне крайне негативного отношения местного населения к приезжим (потенциальным гражданам РФ)1.

Таким образом, Россия сегодня остро нуждается в формировании новых представлений об управлении процессами интеграции иммигрантов и разработке социальных технологий для инкорпорирования иммигрантов путем формирования соответствующих механизмов и процедур с учетом региональных особенностей.

Учитывая особенности исторического развития нашей страны и многонациональный состав ее населения, при разработке стратегии интеграционной политики в области миграции упор стоит сделать на потенциал приграничных регионов, где более всего проявляются все риски, связанные с миграционными потоками извне [Вардомский, Мироненко 1982].

Механизм проведения социологического мониторинга региональной миграционной среды должен включать технику и технологии, методы измерения, в т. ч. статистические и социологические, а также инструменты и инструментарий измерения и анализа качества.

Стоит выделить две составляющие механизма проведения социологического мониторинга региональной миграционной среды: организационную и управленческую. Организационный компонент включает в себя структуру методов и приемов проведения социологического мониторинга миграционной среды, а также их взаимосвязи и взаимозависимости. В свою очередь, управленческий компонент социологического мониторинга объединяет процессы и методы управления проведением исследования, конкретные роли и должностные инструкции субъектов мониторинга, методы управления процессом мониторинга и организационным персоналом. Кроме того, важной частью управленческого компонента является интерпретация и последующее использование результатов организованного мониторинга.

При организации мониторинга миграционных процессов на региональном уровне можно выделить три основных направления проведения исследований:

1) социально-психологическое - в данном случае исследуются значимость этнокультурной идентичности мигрантов, степень вовлеченности в принимающее сообщество, удовлетворенность собственным положением в новом регионе постоянного проживания;

2) этнокультурное - включает в себя изучение сформировавшихся связей мигранта и принимающего сообщества, степень понимания этнокультурных особенностей, характерных для нового региона постоянного проживания;

3) социально-экономическое - направлено на исследование включенности мигранта в социально-экономическую систему региона, наличия или отсутствия работы, уровня материального благосостояния и степени удовлетворенности им.

Следует отметить, что в рамках настоящего подхода особый акцент ставится на этнокультурном и социально-психологическом направлении, тогда как при

1 Россия. Профиль страны МІРЕX. Доступ: https://scr.hse.ru/data/2020/11/19/136542620 8/\%D0\%A0\%D0\%BE\%D1\%81\%D1\%81\%D0\%B8\%D1\%8F \%D0\%9F\%D1\%80\%D0\%BE\%D $1 \% 84 \% \mathrm{D} 0 \% \mathrm{~B} 8 \% \mathrm{D} 0 \% \mathrm{BB} \% \mathrm{D} 1 \% 8 \mathrm{C} \% 20 \% \mathrm{D} 1 \% 81 \% \mathrm{D} 1 \% 82 \% \mathrm{D} 1 \% 80 \% \mathrm{D} 0 \% \mathrm{~B} 0 \% \mathrm{D} 0 \% \mathrm{BD} \% \mathrm{D} 1 \%$ 8B_MIPEX.pdf (проверено 16.05.2021). 
использовании традиционных методик основное внимание уделяется степени интеграции мигранта в социально-экономическую региональную систему. В этой связи базовыми понятиями данного подхода выступают этнокультурная общность и идентичность. Слишком ярко выраженная этнокультурная идентичность мигранта будет затруднять интеграцию в принимающее сообщество. При этом важным является и восприятие характерных черт и особенностей, присущих этнокультурной общности принимающего региона, умение использовать их понимание в повседневной жизни для решения личных проблем.

Одним из основных показателей интеграции мигранта в принимающее сообщество выступает уровень его гражданского и этнического самосознания. То, насколько мигрант отождествляет себя с принимающим сообществом и присущими ему ценностями, культурными символами, паттернами и стилями поведения, определяет уровень интеграции. В этих условиях мигрант должен воспринимать себя как часть принимающего сообщества, принимать непосредственное участие в решении общих проблем, в жизни региона, а также,

Таблица 1

Система индикаторов мониторинга уровня интеграции иммигрантов в региональную среду

\begin{tabular}{|c|c|c|}
\hline $\begin{array}{c}\text { Высокая степень } \\
\text { интегрированности }\end{array}$ & $\begin{array}{c}\text { Средняя степень } \\
\text { интегрированности }\end{array}$ & $\begin{array}{c}\text { Низкая степень } \\
\text { интегрированности }\end{array}$ \\
\hline $\begin{array}{l}\text { 1. Идентификация имми- } \\
\text { грантов как равноправных } \\
\text { субъектов региональных } \\
\text { гражданских процессов }\end{array}$ & $\begin{array}{l}\text { 1. Идентификация имми- } \\
\text { грантов как субъектов } \\
\text { региональных гражданских } \\
\text { процессов, которые имеют } \\
\text { ограниченные права }\end{array}$ & $\begin{array}{l}\text { 1. Открытая дискриминация } \\
\text { иммигрантов как субъектов } \\
\text { региональных гражданских } \\
\text { процессов }\end{array}$ \\
\hline $\begin{array}{l}\text { 2. Отсутс } \\
\text { на межнс }\end{array}$ & $\begin{array}{l}\text { 2. Наличие скрытых кон- } \\
\text { фликтов (напряженности) } \\
\text { на межнациональной почве }\end{array}$ & $\begin{array}{l}\text { 2. Открь } \\
\text { на межн }\end{array}$ \\
\hline $\begin{array}{l}\text { 3.Эффективное сотрудниче- } \\
\text { ство иммигрантов и других } \\
\text { представителей региональ- } \\
\text { ного сообщества на фор-- } \\
\text { мальном и неформальном } \\
\text { уровнях }\end{array}$ & $\begin{array}{l}\text { 3. Сотрудничество имми- } \\
\text { грантов и других представи- } \\
\text { телей регионального сооб- } \\
\text { щества носит вынужденный } \\
\text { характер и не отличается } \\
\text { высокой эффективностью }\end{array}$ & $\begin{array}{l}\text { 3. Отсутствие постоянных } \\
\text { контактов между имми-- } \\
\text { грантами и другими пред- } \\
\text { ставителями регионального } \\
\text { сообщества }\end{array}$ \\
\hline $\begin{array}{l}\text { 4. Позитивное восприятие } \\
\text { иммигрантов как части } \\
\text { регионального сообщества }\end{array}$ & $\begin{array}{l}\text { 4. Наличие отрицательных } \\
\text { стереотипов, связанных } \\
\text { с иммигрантами }\end{array}$ & $\begin{array}{l}\text { 4. Негативное восприятие } \\
\text { иммигрантов как части } \\
\text { регионального сообщества }\end{array}$ \\
\hline $\begin{array}{l}\text { 5. Полная удовлетворен- } \\
\text { ность иммигранта своим } \\
\text { статусом в региональном } \\
\text { сообществе }\end{array}$ & $\begin{array}{l}\text { 5.Частичная удовлетворен- } \\
\text { ность иммигранта своим } \\
\text { статусом в региональном } \\
\text { сообществе }\end{array}$ & $\begin{array}{l}\text { 5. Неудовлетворенность } \\
\text { иммигрантов своим ста- } \\
\text { тусом в региональном } \\
\text { сообществе }\end{array}$ \\
\hline $\begin{array}{l}\text { 6. Понимание особенностей } \\
\text { принимающей культуры, } \\
\text { комфортность взаимодей- } \\
\text { ствия с неродной культурой }\end{array}$ & $\begin{array}{l}\text { 6. Состояние тревожности } \\
\text { и неуверенности при вза- } \\
\text { имодействии с неродной } \\
\text { культурой }\end{array}$ & $\begin{array}{l}\text { 6. Культурная сегрегация } \\
\text { /сепарация }\end{array}$ \\
\hline $\begin{array}{l}\text { 7. Обретение иммигрантами } \\
\text { региональной идентичности }\end{array}$ & $\begin{array}{l}\text { 7. Этническая маргиналь- } \\
\text { ность иммигрантов }\end{array}$ & $\begin{array}{l}\text { 7. Негативное восприятие } \\
\text { этнической идентичности } \\
\text { иммигрантами }\end{array}$ \\
\hline $\begin{array}{l}\text { 8. Устойчивое стремление к } \\
\text { освоению социокультурного } \\
\text { пространства региона }\end{array}$ & $\begin{array}{l}\text { 8. Стремление к освоению } \\
\text { социокультурного про- } \\
\text { странства региона ситуа- } \\
\text { тивно и нечетко выражено }\end{array}$ & $\begin{array}{l}\text { 8. Индифферентное отно- } \\
\text { шение к освоению социо- } \\
\text { культурного пространства } \\
\text { региона }\end{array}$ \\
\hline
\end{tabular}


пусть и частично, иметь общие элементы идентичности [Горбунова, Максимов 2019].

По нашему мнению, систему индикаторов мониторинга уровня интеграции иммигрантов в региональную среду возможно представить в виде таблицы (см. табл. 1).

Применяя на практике данные критерии мониторинга, стоит учитывать, что интеграция иммигрантов - это всегда встречный процесс, где гораздо более длительный путь всегда проходят иммигранты и их семьи.

Таким образом, на основании изложенного представляется возможным сформулировать следующие выводы.

1. Россия сегодня нуждается в значительной модернизации интеграционной политики в сфере миграции на всех уровнях.

2. Эффективная реализация интеграционной политики возможна исключительно с учетом миграционного потенциала каждого отдельно взятого региона.

3. Особую роль в эффективном формировании и реализации политики интеграции иммигрантов играют приграничные регионы. В этих условиях необходима разработка и внедрение системы мониторинга региональной миграционной среды, не только включающей диагностику региональных проблем миграционной политики, но и позволяющей сформировать гибкий инструментарий поддержки интеграции иммигрантов.

4. Результатом таких мер станет формирование в приграничных регионах единой субъектной управляющей системы, в которую должны быть объединены все функционирующие на территории организационные структуры (органы государственной власти и управления, общественные, юридические, этнические, экономические и другие институты) различных видов и типов, реализующие свои функции в регулировании интеграционных процессов.

\footnotetext{
Статья подготовлена в рамках проекта МД-578.2020.6 «Социокультурные угрозы трансформации иивилизационных фронтиров в постсоветскомхронотопе» приподдержкегранта Президента Российской Федерации для государственной поддержки молодых российских ученых - докторов наук.
}

\section{Список литературы}

Бормотова Т.М. 2020. Миграционные процессы в приграничных регионах России: состояние и специфика. - Этносоциум и межнациональная культура. № 7. С. 9-17.

Вардомский Л.Б., Мироненко Н.С. 1982. К проблеме изучения грании экономико-географических систем. М.: Изд-во МГУ. 128 с.

Горбунова А.А., Максимов М.М. 2019. Адаптационный потенциал национальных диаспор в приграничных регионах России. - Society and Security Insights. № 2. C. 31-41.

Малахов В.С. 2015. Интеграция мигрантов: Концепции и практики. М.: Фонд «Либеральная Миссия». 272 с.

Межевич Н.М. 2006. Границы в современном мире: новые качества в условиях глобализации. Псковский регионологический журнал. № 3. С. 3-13.

Мигранты, мигрантофобии имиграционная политика (отв. ред. В.И. Мукомель). 2014. М.: НП «Центральный Дом адвоката», Московское бюро по правам человека; Academia. 245 c.

Мукомель В.И. 2016. Адаптация и интеграция мигрантов: методологические подходы к оценке результативности и роль принимающего общества. - Россия реформирующаяся. № 14. С. 411-467. 
OLEINIK Svetlana Anatol'evna, Applicant at the Chair of Social Technologies and Public Service, Belgorod National Research University (85 Pobedy St, Belgorod, Russia, 308015)

\title{
FEATURES OF THE STATE POLICY OF INTEGRATION OF IMMIGRANTS IN THE BORDER REGIONS
}

\begin{abstract}
The article discusses various features of the implementation of state migration policy in relation to migrants in border regions. The paper notes that the effective implementation of the integration policy is only possible taking into account the migration potential of each individual region and especially emphasizes the need for a policy aimed at integrating migrants into the host community. The author concludes that one of the key tasks of state policy in this area should be the organization of regular monitoring of the migration environment of borderlands based on 3 groups of indicators: sociopsychological, ethnocultural and socio-economic ones.

The mechanism for conducting sociological monitoring of the regional migration environment should include equipment and technologies, measurement methods, including statistical and sociological ones, as well as tools and instruments for measuring and analyzing quality. The author proposes to create a unified management system in the border regions, in the work of which all state and public entities carrying out activities in the field of integration of migrants should be involved. Keywords: migration processes, integration of migrants, border regions
\end{abstract}

ПАРМА Роман Васильевич - кандидат политических наук, доцент департамента политологии факультета социальных наук и массовых коммуникаций Финансового университета при Правительстве РФ (125993, Россия, г. Москва, Ленинградский пр-кт, 49, r.parma@таil.ru) КОЗЛОВ Никита Александрович - студент 3-го курса факультета социальных наук и массовых коммуникаций Финансового университета при Правительстве РФ (125993, Россия, г. Москва, Ленинградский np-кm, 49, kozlovn_54@mail.ru)

\section{ПОСТРОЕНИЕ МОДЕЛИ ВОЗДЕЙСТВИЯ КРЕДИТНОЙ НАГРУЗКИ НА ПОЛИТИЧЕСКОЕ ПОВЕДЕНИЕ РОССИЙСКИХ ГРАЖДАН}

\begin{abstract}
Аннотация. В данной статье рассматривается влияние кредитных обязательств граждан на их когнитивные установки и политическое поведение. На основании статистики Центрального банка РФ определяется циклический характер развития рынка розничного кредитования, обусловливающий периодическое возрастание рисков дестабилизации политической ситуации. Посредством анализа результатов научных исследований авторы показывают, как трудности с погашением кредитной задолженности могут провоцировать состояние стресса, эмоции тревоги и гнева, формировать пессимистические установки в отношении будущего, вызывать политические проявления недовольства и протеста. В статье определяются основные переменные динамической модели взаимосвязи кредитной нагрузки и политического поведения граждан.
\end{abstract}

Ключевые слова: кредитная нагрузка, закредитованность граждан, финансовые заемщики, политическое поведение, когнитивные установки, эмоции индивидов, протестные настроения.

Dacсмотрение кредитной динамики остается прерогативой экономических исследований. Однако институт кредитования граждан содержит в себе неотъемлемый политический компонент. Кредитное бремя ставит наиболее 